\title{
FEATURES OF THE DEVELOPMENT OF A LYOPHILIZED INJECTABLE DOSAGE FORM OF THE ORIGINAL ANTICANCER DRUG LCS-1208
}

\section{ILYA GULYAKIN ${ }^{1}$, ANNA LANTSOVA ${ }^{2}$, LYUDMILA NIKOLAEVA ${ }^{1,2}$, MARIA DMITRIEVA ${ }^{2}$, NATALIYA OBOROTOVA ${ }^{2}$, OLGA ORLOVA ${ }^{2}$, NATALIA ZHURAVLEVA ${ }^{2}$}

1Sechenov University, 8/2 Trubeckaya Str., Moscow, 119991, Russia, ${ }^{2}$ N. N. Blokhin National Medical Research Center of Oncology, 24 Kashirskoye Sh., Moscow, 115478, Russia

Email: alima91@yandex.ru

Received: 09 Mar 2021, Revised and Accepted: 12 Apr 2021

ABSTRACT

Objective: Development of a lyophilized injectable dosage form LCS-1208, an original antitumor drug based on an indolocarbazole derivative.

Methods: The prepared solution of the injectable dosage form LCS-1208 is transferred to sterilizing filtration, which is carried out under vacuum on a «Stericup» filter unit with a filter pore size of $0.22 \mu \mathrm{m}$. The sterile solution of the injectable dosage form LCS-1208 is poured into sterile vials using a dispenser and lyophilized in a freeze-drying chamber. At the end of drying, the preparation is corked in the chamber of a sublimation unit using a hydraulic device and transferred to crimping with aluminum caps using a seaming machine. Quantitative determination of the drug content was determined by spectrophotometry using a standard sample at $\lambda=320 \pm 2 \mathrm{~nm}$. The $\mathrm{pH}$ was determined by potentiometry.

Results: A freeze-drying regimen for the injectable dosage form LCS-1208 has been developed. The required solution freezing temperature was established taking into account the presence of 2 eutectic zones: a solution of LCS-1208 in DMSO $(-35 \div-32){ }^{\circ} \mathrm{C}$, an aqueous solution of Kollidon $17 \mathrm{PF}$ $(-10 \div-8)^{\circ} \mathrm{C}$. As a result of a series of experiments, the optimal lyophilization regime was chosen that does not require preliminary freezing in a lowtemperature chamber, with freezing on the shelves of freeze-drying at a temperature of- $47{ }^{\circ} \mathrm{C}$ without their preliminary cooling. The most acceptable vial filling volume was determined, amounting to $3 \mathrm{ml}$, and the rate of temperature rise during secondary drying of the preparation was justified. When using the developed regime of lyophilization of the LCS-1208 solution, it was shown that it can be sublimated while preserving the initial qualitative and quantitative characteristics.

Conclusion: In this article, using the example of creating a lyophilized injectable dosage form LCS-1208 (the original antitumor drug from the indolocarbazole group), the main problems that arose during the lyophilization of the selected composition of the model solution, as well as ways to improve the process.

Keywords: Lyophilization, LCS-1208, Freeze-drying, Lyophilisate for parenteral use

(C) 2021 The Authors. Published by Innovare Academic Sciences Pvt Ltd. This is an open access article under the CC BY license (https://creativecommons.org/licenses/by/4.0/) DOI: https://dx.doi.org/10.22159/ijap.2021v13i4.41371. Journal homepage: https://innovareacademics.in/journals/index.php/ijap

\section{INTRODUCTION}

Lyophilization is a process that has frequent problems at the stage of development and production of the dosage form; risks at control points are especially numerous. In this regard, there is a need to systematize knowledge and understanding of the components of this process, namely freezing and freeze-drying, mechanisms of heat and mass transfer processes occurring at different stages of lyophilization. The main ways to improve the lyophilization process is to optimize the technological aspects of drying and directly select auxiliary substances, based on the physicochemical basis of the process [1-3].

These approaches are considered by the example of the development of a lyophilized injection dosage form (ILF-lyo) LCS-1208, an original antitumor drug based on an indolocarbazole derivative [4].

The main influence on the quality of the finished dosage forms in the form of a lyophilisate for the preparation of a solution for injection is exerted by technological factors and excipients. Both are interconnected. So the composition and amount of excipients in lyophilization technology affect the choice of temperature conditions for freezing and freeze-drying, the stability of both the starting substance and the resulting product. For example, if the contents of the operating substance are small or significant, the subject of lyophilization is, it is small in water or water-alcohol mixture, a dosage form is introduced into the composition of the dosage form filler. In quality of such fillings, most often use high molecular weight compounds, polyvinylpyrrolidone (PVP) [5]; carbohydrates-sucrose, lactose; carbohydrate-containing alcoholsmannitol, sorbitol; glycine and others.

Depending on the properties, these substances perform other functions: they affect the freezing process (for example, sugars, polymers, alcohols, lower the freezing point of water and slow down its crystallization), change the eutectic point, the drying speed and the final residual moisture $[6,7]$.

The first technological step in the production of injectable lyophilized drugs is to prepare a solution to be dried. In this regard, the physicochemical properties of the active substance (pharmaceutical substance) and possible ways of its destruction in the aquatic environment are studied, auxiliary components necessary in each specific case are selected [8].

The lyophilization process consists of three main stages. The first stage is freezing, which involves directly crystallizing the product and creating a strong matrix suitable for drying.

The second stage is primary drying, which is sometimes preceded by an additional stage, called "annealing" or thermal cycling. Primary drying involves the removal of ice by sublimation while reducing the ambient pressure of the product and temperature $[9,10]$.

In the third stage-secondary drying-the bound water is removed until the residual moisture content reaches its target level, ensuring the integrity of the obtained lyophilisate tablet. [11-13].

The aim of this study was the development of a lyophilized injectable dosage form LCS-1208, an original antitumor drug based on an indolocarbazole derivative.

\section{MATERIALS AND METHODS}

\section{Object of study}

In the studies, a model solution was used containing, as the active substance, the substance of the indolocarbazole derivative LCS- 
1208-6-amino-12-(1- $\alpha$-L-arabinopyranosyl)indolo[2,3a]pyrrolo $[3,4 c]$ carbazole-5,7-dion created by specialists of the Research Institute of Experimental Diagnosis and Treatment of Tumors of the Federal State Budgetary Institution «N. N. Blokhin National Medical Research Centre of oncology» of the Health Ministry of Russian Federation (fig. 1). The substance LCS-1208 is soluble in water, slightly soluble in $95 \%$ alcohol and acetone, soluble in dimethyl sulfoxide (DMSO) and dimethylformamide.

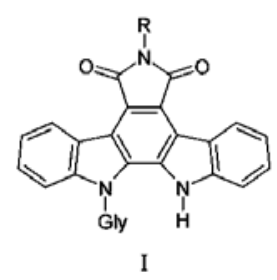

Fig. 1: The general formula of the indolocarbazole derivative LCS-1208, where $\mathrm{R}-\mathrm{NH}_{2}$, Gly-arabinose

The solvent used was DMSO (Himmed, Russian Federation), the cryoprotectant and cosolvent was Kollidon 17 PF (PVP, povidone) (BASF The Chemical Company, Germany).

\section{Equipment}

Freeze-drying Minifast 10 (Edwards, Great Britain, Italy); lowtemperature chamber NZ 280/75. A (Frigera, Czech Republic); Cary 100 spectrophotometer (Varian, Inc., Australia); HANNA pH meter pH 211 (Hanna Instruments, Germany); semiautomatic device PZR34-VIPS-MED for corking vials with caps K-2-20 and K-3-34 (LLC "ViPS-MED Company», Russian Federation); Stericup GP Millipore Express Plus filtration system with $0.22 \mu \mathrm{m}$ polyethersulfone filters (Merck KGaA, Germany).

\section{Preparation of substance LCS-1208}

To 0.55 g $(0.9 \mathrm{mmol}) \quad 13$-formyl-12-(2,3,4-tri-O-acetyl- $\alpha$-Larabinopyranosyl)indolo[2,3-a]furano[3,4-c]carbazole-5,7-dione added $3.2 \mathrm{ml}(65.25 \mathrm{mmol})$ of hydrazine hydrate, the mixture was kept at $50{ }^{\circ} \mathrm{C}$ for two hours, cooled to $22{ }^{\circ} \mathrm{C}$, poured into water. The precipitate was filtered off, washed with $10 \%$ alcohol. The yield of 6 amino-12-( $\alpha$-L-arabinopyranosyl)indolo[2,3-a]pyrrolo [3,4c]carbazole-5,7-dione was $0.37 \mathrm{~g}(89 \%)$.

\section{RESULTS AND DISCUSSION}

The optimal inject able dosage form (IDF) regimen LCS-1208 was chosen empirically after a series of experiments and subsequent physicochemical control of the finished product based on studies in different modes.

In developing the optimal drying regime, LCS-1208 first investigated the effect of the initial temperature and its rise rate on the quality of the finished product, including its appearance, the preservation of the properties of the substance, the thickness of the initial solution layer, and the ability to rehydrate. To develop a lyophilization regime, the freezing conditions (its duration and method) of the LCS1208 model solution were initially selected, and the initial freezing temperature was determined for this purpose.

When developing lyophilization technology to establish the required freezing temperature of a solution, it is necessary to determine the eutectic temperature, which has a specific value for each substance in the case of eutectic forming solutions or the eutectic zone for «glassforming» substances. Usually, the freezing temperature for reliability is taken $5-10{ }^{\circ} \mathrm{C}$ below the eutectic. The thermal method used to determine the eutectic temperature is the simplest. It is based on fixing the temperature of a sample frozen below a eutectic point during slow thawing. On the curve of measuring the temperature of the material upon reaching the eutectic point, a plateau is formed corresponding to the time when the heat supplied from outside does not increase the temperature but is spent on melting ice at a given eutectic «concentration» of the solution. Such a site can only be obtained with a sufficiently high content of the substance in the solution, therefore this method is not applicable in all cases.

When determining the eutectic temperature, delamination of the frozen LCS-1208 model solution was observed. When the temperature reached $(-42 \div-40){ }^{\circ} \mathrm{C}$, partial thawing was observed, and at $(-35 \div-32){ }^{\circ} \mathrm{C}$, a bright yellow solution was formed in the lower layer of the frozen mass. The rest of the mass was thawed at a temperature of $(-10 \div-8){ }^{\circ} \mathrm{C}$, which indicated the presence of 2 eutectic zones. Obviously, a higher eutectic zone had an aqueous Kollidon 17PF solution, and at a lower one, the LCS-1208 solution distributed in it in DMSO froze. The difficulty of freezing and sublimation of this model solution is that DMSO is an antifreeze, therefore it freezes at very low temperatures.

A key parameter in the final stage of primary drying is the selection of the optimal rate of heating of the lyophilisate. At low rates of heating and sublimation, the energy consumption of this stage increases, at high-the likelihood of destruction of the tablet by residual moisture increases. Therefore, to go to the secondary drying stage, a gradual slow temperature increase is necessary, which correlates with a change in the rate of evaporation of residual moisture.

During secondary drying, the rate of temperature rise and the drying time of the product was studied. With the intensification of the secondary drying process by increasing the rate of temperature rise to $+10^{\circ} \mathrm{C} / \mathrm{h}$ and increasing the temperature upon drying to $+22^{\circ} \mathrm{C}$, a decrease in the content of the active substance LCS-1208 in the vial was observed below acceptable limits. Reducing the intensity of heating to $5{ }^{\circ} \mathrm{C} / \mathrm{h}$ and increasing the drying time also did not provide guaranteed product quality.

As a result of a visual assessment of the appearance of the accumulated batches of IDF LCS-1208 (with the maximum possible filling volume of the vials $-6 \mathrm{ml}$ ) in accordance with the previously selected regime, it was found that thawed vials were found among the total mass of lyophilisates. In this regard, it was decided to choose the optimal volume of filling the vials with LCS-1208 solution and improve its lyophilization mode.

For studies used the volume of filling the vials: 2, 3, 4, 5, $6 \mathrm{ml}$ and various modes of lyophilization:

1) with a preliminary long-term (12 h) freezing of the LCS-1208 solution in a low-temperature chamber at a temperature of $-45{ }^{\circ} \mathrm{C}$ and installation of vials on freeze-drying shelves, previously cooled for 1 hour at a temperature of $-47^{\circ} \mathrm{C}($ mode 1$)$;

2) without preliminary freezing in a low-temperature chamber, with freezing at a temperature of- $45{ }^{\circ} \mathrm{C}$ on shelves of freeze-drying, precooled for 1 hour at a temperature of $-47^{\circ} \mathrm{C}$ (mode 2);

3) without preliminary freezing in a low-temperature chamber, with freezing on the shelves of freeze-drying at a temperature of- $45{ }^{\circ} \mathrm{C}$ without their preliminary cooling (mode 3 ).

Evaluated the effectiveness of the proposed regimes on the level of defective products (the number of melted vials in relation to the total number of dried vials), which was determined visually. As a result of a series of freeze-dried dryers, according to three modes with the different filling of the vials, it turned out that with filling volumes of 2 and $3 \mathrm{ml}$, the lyophilization regime did not affect the level of defective products; at the same time, the critical volume of filling the vials, which does not allow to ensure the absence of marriage- $4 \mathrm{ml}$. Based on these results, the volume of $3 \mathrm{ml}$ was chosen as the optimal one. Since the change in the freezing mode did not have a significant effect on the level of defective products, it was decided not to pre-freeze the LCS-1208 solution, but to cool the preparation on freeze-dried shelves without their preliminary cooling (mode 3).

This mode was tested on a Minifast 10 freeze-dryer. Conducting lyophilization according to the selected mode on this unit provided a high-quality lyophilisate, which is a dry yellow porous mass, from a solution of $3 \mathrm{ml}$ each. The solution obtained after dissolving the lyophilisate LCS-1208 is stable in terms of appearance, $\mathrm{pH}$, and the content of the active substance during the day (sufficient for the use of the drug). 
The results of preclinical studies IDF-lyo LCS-1208, conducted by employees of the N. N. Blokhin National Medical Research Centre of oncology are the optimal modes of application of the developed dosage form for tumors of various histogenesis (table 1) [14].

Table 1: Modes of use of IDF-lyo LCS-1208 for intravenous administration

\begin{tabular}{lll}
\hline Transplanted tumors & Dose & The optimal mode of administration \\
\hline $\begin{array}{l}\text { Hemoblastoses R-388 and L-1210 } \\
\text { Fisher's lymphadenosis L 5178Y }\end{array}$ & $25 \mathrm{mg} / \mathrm{kg}$ & daily intravenous administration (within 5 d) \\
$\begin{array}{l}\text { Lewis Epidermoid Carcinoma LLC } \\
\text { Cervical cancer CC-5 }\end{array}$ & $150 \mathrm{mg} / \mathrm{kg}$ & single intravenous administration \\
Melanoma B-16 & &
\end{tabular}

The advantage of the lyophilized injectable dosage form LCS-1208 on the duration of the antitumor effect was established compared with irinotecan, a well-known topoisomerase I inhibitor (table 2).
The combination of LCS-1208 with irinotecan at doses half the therapeutic dose of combinants $(75 \mathrm{mg} / \mathrm{kg}$ and $33 \mathrm{mg} / \mathrm{kg}$, respectively) causes a synergistic antitumor effect [15].

Table 2: The advantage of IDF-lyo LCS-1208 on the duration of the antitumor effect compared with irinotecan

\begin{tabular}{lll}
\hline Drug & Tumor growth inhibition \\
\cline { 2 - 2 } & Within 20 d of treatment & After treatment \\
\hline LCS-1208 & $95 \%$ & $94 \%$ \\
Irinotecan (Campto@-Pfizer (Perth) Pti Ltd.) & $52 \%$ & $27 \%$ \\
\hline
\end{tabular}

In the study of «acute» toxicity, it was found that with the use of IDFlyo LCS-1208 in a fixed concentration and the maximum possible volume intravenously in mice and intravenously and intraperitoneally to rats, no animal death was observed, therefore, the calculated toxic doses of IDF-lyo LCS-1208 were not obtained [16]. The subchronic toxicity of IDF-lyo LCS-1208 was studied with 15-fold daily intraperitoneal administration to rats in total doses of 50,100 and $200 \mathrm{mg} / \mathrm{kg}$ for $15 \mathrm{~d}$, which did not cause the death of animals, did not affect their general condition and did not cause external manifestations of toxicity [17]. Thus, the use of IDF-lyo LCS1208 is safe and may be recommended for further clinical studies.

Based on experimental studies, the following technological processes (TP) were developed for obtaining a sterile solution LCS1208 and its further lyophilization:

\section{TP-1. Obtaining a sterile solution LCS-1208}

\section{TP-1.1. Preparation of PVP solution}

In a glass cup with a capacity of $2 \mathrm{l}, 1360 \mathrm{ml}$ of water for injection is measured with a graduated cylinder. A portion of PVP (336.0 g), taken on an electronic balance in a glass beaker with a capacity of 1 liter, is poured in parts onto a surface of the water, and the solution is mixed with a propeller stirrer, and then left to dissolve completely. Dissolution time about 20-30 min.

\section{TP-1.2. Preparation of LCS-1208 solution}

A portion of LCS-1208 $5.04 \mathrm{~g}$ is weighed on an electronic balance in a glass glass with a capacity of $100 \mathrm{ml} .84 .0 \mathrm{ml}$ of DMSO measured by a cylinder was added to a LCS-1208 sample, mixed thoroughly with a glass rod. The resulting solution is added in portions to the PVP solution with constant stirring on a propeller stirrer. The LCS-1208 solution is colored in orange and has a final volume of $1680 \mathrm{ml}$. Dissolution time 20-30 min. The solution is passed to the filtration.

\section{TP-1.3. LCS-1208 solution filtration and vial filling}

\subsubsection{Sterilizing filtration solution LCS-1208}

Before filtering, the integrity of the filter is checked using a «bubble» test. The filter is considered to be intact and suitable for use if gas bubbles do not pass through the liquid layer when conducting a «bubble» test. Sterilizing filtration is carried out under vacuum on a «Stericup» filter unit with a filter pore size of $0.22 \mu \mathrm{m}$. Filtration time about 20-30 min. The resulting solution, which has an orange color, is transmitted for analysis. The filtered solution is passed to the bottling.

TP-1.3.2. Bottling sterile LCS-1208 solution in vials and pre-capping

The sterile LCS-1208 solution is poured into $3.0 \mathrm{ml}$ into sterile vials with a capacity of $20 \mathrm{ml}$ using a dispenser. The first 4-5 doses of the solution, comprising 12-15 ml are discarded. Before bottling, check the correct operation of the dispenser. For this, 5 doses of the concentrate are measured in a dry graduated cylinder with a capacity of $25 \mathrm{ml}$. A deviation of $\pm 0.1 \mathrm{ml}$ is allowed for a $3 \mathrm{ml}$ solution. The correct operation of the dispenser is carried out periodically during the entire filling cycle (3-4 times). The LCS-1208 solution used to test the dispenser is returned for repeated sterile filtration. Manual preliminary capping of the vials with the drug is carried out. Pre-sealed vials with a sterile LCS-1208 solution are placed in metal cassettes. Sensors are installed in two vials with LCS1208 solution and transferred for freezing.

\section{TP-2. Getting the finished product}

\section{TP-2.1. Freezing}

Cassettes with vials are placed on the shelf of the Minifast 10 sublimation unit, the sensors installed in the vials are connected, the chamber of the sublimation unit is closed and the product begins to freeze. Initial freezing temperature $(-47 \div-50){ }^{\circ} \mathrm{C}$. After the temperature has been set on the preparation, the set temperature is held for 12-15 h. Monitoring temperature and duration of freezing by recording devices (vacuum gauge; six-channel recorder).

\section{TP-2.2. Freeze drying}

Initial drying temperature $(-47 \div-50){ }^{\circ} \mathrm{C}$. Shelves are heated to a temperature of $+20^{\circ} \mathrm{C} 3 \mathrm{~h}$ after turning on the vacuum pump and equalizing the vacuum. The maximum possible rate of temperature rise is $1{ }^{\circ} \mathrm{C} /$ hour to a temperature of $-25{ }^{\circ} \mathrm{C}$. Then raise the temperature of the shelves $5{ }^{\circ} \mathrm{C} \mathrm{C}$ /hour to a temperature of $+20{ }^{\circ} \mathrm{C}$. Duration of drying-from 3 to $5 \mathrm{~h}$. After drying, air injection is switched on and the residual pressure in the chamber is adjusted to a value of 40-50 $\mathrm{Pa}$. The temperature on the preparation during drying should not exceed $+20^{\circ} \mathrm{C}$. The total drying time of the drug in vials with a capacity of $20 \mathrm{ml}$ is $48-50 \mathrm{~h}$. The control of the freezedrying process is carried out by the operator for the instruments and the recording device located on the installation panel. After drying, the vacuum in the sublimation chamber is quenched with clean, filtered air that enters the chamber through a filter system. The drug is corked in a sublimation chamber using a hydraulic device and transferred to crimping with aluminum caps.

\section{TP-2.3. Crimping with caps}

Crimping the vials with aluminum caps is carried out using a seaming machine in a room of cleanliness class B. Rolled vials are placed in cassettes and transferred to the stage of packaging and processing of finished products.

\section{CONCLUSION}

A freeze-drying regimen for the injectable dosage form LCS-1208 has been developed. The required solution freezing temperature 
was established taking into account the presence of 2 eutectic zones: a LCS-1208 solution in DMSO $(-35 \div-32){ }^{\circ} \mathrm{C}$, an aqueous Kollidon $17 \mathrm{PF}$ solution $(-10 \div-8)^{\circ} \mathrm{C}$. As a result of a series of experiments, the optimal lyophilization regime was chosen that does not require preliminary freezing in a low-temperature chamber, with freezing on the shelves of freeze-drying at a temperature of- $47{ }^{\circ} \mathrm{C}$ without their preliminary cooling. The most acceptable vial filling volume was determined, amounting to $3 \mathrm{ml}$, and the rate of temperature rise during secondary drying of the preparation was justified. Using the developed regime of lyophilization of the LCS-1208 solution, it was shown that it can be sublimated while maintaining the initial qualitative and quantitative characteristics. The results of preclinical and toxicological studies IDF-lyo LCS-1208, conducted by employees of the Research Institute of Experimental Diagnosis and Treatment of Tumors of the Federal State Budgetary Institution «N. N. Blokhin National Medical Research Centre of oncology» of the Health Ministry of Russian Federation, confirm the effectiveness and safety of the use of IDF-lyo LCS-1208 for further clinical studies.

\section{ACKNOWLEDGMENT}

The work was performed as part of State contract No. 13411.1008799.13.20 of 06.24.13. «Preclinical studies of innovative drugs on based indolocarbazole derivative for the treatment of cancer».

\section{FUNDING}

Nil

\section{AUTHORS CONTRIBUTIONS}

All the authors have contributed equally.

\section{CONFLICT OF INTERESTS}

Declared none

\section{REFERENCES}

1. Blynskaya EV, Tishkov SV, Alekseev KV. Technological approaches to improving the process of lyophilization of protein and peptide drugs. Russ J Biother 2017;16:6-11.

2. Carpenter JF, Chang BS, Garzon Rodriguez W, Randolph TW. Rational design of stable lyophilized protein formulations: theory and practice. In: Carpenter JF, Manning MC. editors. Rational design of stable protein formulations. Pharmaceutical Biotechnology. Vol 13. Springer, Boston, MA; 2002. https://doi.org/10.1007/978-1-4615-0557-0_5

3. Tang XC, Pikal MJ. Design of freeze-drying processes for pharmaceuticals: practical advice. Pharm Res 2004;21:191200.
4. Gulyakin ID, Nikolaeva LL, Dmitrieva MV. Obtaining and analysis of the lyophilized dosage form LCS-1208 by thin-layer chromatography and spectrophotometry. Drug Dev Reg 2016;17:62-7.

5. Chang LL, Shepherd D, Sun J. Mechanism of protein stabilization by sugars during freeze-drying and storage: native structure preservation, specific interaction, and/or immobilization in a glassy matrix? J Pharm Sci 2005;94:1427-44.

6. Arshinova OYu, Oborotova NA, Sanarova EV. Excipients in the technology of lyophilization of drugs. Drug Dev Reg 2013;2:20-5.

7. Chang BS, Patro SY. Freeze-drying process development for protein pharmaceuticals. In: Costantino HR, Pikal MJ. editors. Lyophilization of biopharmaceuticals. American Association of Pharmaceutical Scientists, Arlington; 2004. p. 113-8.

8. Klochkova TI, Shprakh ZS. Organization, scaling and optimization of the production of lyophilized preparations. Russ J Biother 2006;5:115-22.

9. Overcashier DE, Patapoff TW, Hsu CC. Lyophilization of protein formulations in vials: Investigation of the relationship between resistance to vapor flow during primary drying and small-scale product collapse. J Pharm Sci 1999;88:688-95.

10. Searles JA, Carpenter JF, Randolph TW. Annealing to optimize the primary drying rate, reduce freezing-induced drying rate heterogeneity, and determine ifrg $\mathrm{p}$ harmaceutical lyophilization. J Pharm Sci 2001;90:872-87.

11. Arshinova O Yu, Sanarova EV, Lantsova AV. Lyophilization of liposomal drug forms (review). Pharm Chem J 2012;46:29-34.

12. Hottot A, Vessot $S$, Andrieu J. Freeze-drying of pharmaceuticals in vials: influence of freezing protocol and sample configuration on ice morphology and freeze-dried cake texture. Chem Eng Proc: Process Intensification 2007;46:666-74.

13. Liu J. Physical characterization of pharmaceutical formulations in frozen and freeze-dried solid states: techniques and applications in freeze-drying development. Pharm Dev Technol 2006;11:3-28.

14. Kiseleva MP, Shprah ZS, Borisova LM. Preclinical study of indolocarbazole N-glycosides derivative LCS-1208 antitumor activity. Report I. Russ J Biother 2015;14:71-7.

15. Kiseleva MP, Shprah ZS, Borisova LM. Preclinical study of the antitumor activity of indolocarbazole $\mathrm{N}$-glycosides derivative of LCS-1208. Report II. Russ J Biother 2015;14:41-8.

16. Nikolina AA, Kul'Bachevskaya NYu, Konjaeva OI. Study of acute toxicity of novel antitumor preparation based on derivative of indolocarbazole-LCS-1208. Russ J Biother 2015;14:59-64.

17. Nikolina AA, Kul'Bachevskaya NYu, Konjaeva OI. Research of subchronic toxicity in rats of glycoside derivative of indolocarbazole LCS-1208. Russ J Biother 2016;15:62-9. 